\begin{tabular}{|l|l|}
\hline \begin{tabular}{l|l|} 
ESCOLA DE COMUNICAÇÃO, \\
ARTES E DESIGN
\end{tabular} & $\begin{array}{l}\text { mídia, cultura e tecnologia } \\
\text { Revista FAMECOS, Porto Alegre, v. 27, p. 1-13, jan.-dez. } 2020 \\
\text { PUCRS }\end{array}$ \\
$\begin{array}{ll}\text { FAMECOS } \\
\text { e-ISSN: 1980-3729 | ISSN-L: 1415-0549 }\end{array}$ \\
\hline https://dx.doi.org/10.15448/1980-3729.2020.1.36716 \\
\hline
\end{tabular}

CIBERCULTURA

\title{
Fansubbers brasileiros e suas políticas de mediação nas redes digitais
}

\author{
Brazilian fansubbers and their mediation policies on digital networks \\ Fansubbers brasileños y sus políticas de mediación en redes digitales
}

\author{
Krystal Cortez Luz \\ Urbano ${ }^{1}$ \\ 0000-0002-0918-8383 \\ krystal.cortez@gmail.com
}

Recebido em: 24/12/2019. Aprovado em: 12/6/2020. Publicado em: 7/01/2021.

\begin{abstract}
Resumo: O artigo discute as práticas do fandom on-line de animês, com enfoque particular no circuito alimentado pelos fansubbers e seu sistema de colaboração, que consiste na tradução, legendagem e distribuição informal de produtos audiovisuais da Ásia oriental - geralmente animês - no universo das redes digitais. A partir de uma pesquisa com inspiração etnográfica com os agentes envolvidos na atividade de tradução e de distribuição desses produtos no Brasil, o texto apresenta as politicas ativas e plurais que norteiam a atividade colaborativa dos fansubbers locais e que, por sua vez, denunciam uma disputa por capital subcultural própria a esses fãs-produtores em suas comunidades on-line. Fundamentalmente, o artigo apresenta um contraponto à ideia da cultura de fãs de animês representada pelos fansubbers brasileiros como uma comunidade homogênea, com motivações e condutas em comum partilhadas. Palavras-chave: Capital subcultural. Mediação cultural. Fansubbers.
\end{abstract}

Abstract: The article discusses anime online fandom practices, with a particular focus on the fan-powered circuit and its collaboration system, which consists of the translation, subtitling and informal distribution of East Asian audiovisual products - usually anime - in the network universe digital. From an ethnographic inspired research with the agents involved in the translation and distribution activity of these products in Brazil, the text presents the active and plural policies that guide the collaborative activity of local fansubbers and, in turn, denounce a dispute for subcultural capital to these fan producers in their online communities. Fundamentally, the article contrasts with the idea of anime fan culture represented by brazilian fansubbers as a homogeneous community, with shared motivations and common conduct.

Keywords: Subcultural capital. Cultural mediation. Fansubbers.

Resumen: El artículo analiza las prácticas de fandom en línea de anime, con un enfoque particular en el circuito alimentado por fansubbers y su sistema de colaboración, que consiste en la traducción, subtitulación y distribución informal de productos audiovisuales de Asia Oriental, generalmente anime, en el universo de la red digital A partir de una investigación de inspiración etnográfica con los agentes involucrados en la actividad de traducción y distribución de estos productos en Brasil, el texto presenta las politicas activas y plurales que guian la actividad de colaboración de fansubbers locales y, a su vez, denuncian una disputa por capital subcultural para estos productores de fanáticos en sus comunidades en línea. Fundamentalmente, el artículo contrasta con la idea de la cultura de fanáticos del anime representada por fansubbers brasilenos como una comunidad homogénea con motivaciones y comportamientos compartidos. Palabras clave: Capital subcultural. Mediación cultural. Fansubbers. 


\section{Introdução}

O presente artigo teve sua origem em uma pesquisa desenvolvida em âmbito de mestrado, cujo objetivo foi investigar as práticas contemporâneas do fandom de animês ${ }^{2}$ no Brasil, especialmente associado ao universo das redes digitais. Para tal intento, optei em dar enfoque na prática desenvolvida pelos fansubbers ${ }^{3}$ e seu sistema de colaboração, que consiste na tradução, legendagem e distribuição informal de produtos audiovisuais da Ásia oriental - geralmente animês - no universo das redes digitais (URBANO, 2013). Embora a discussão do texto esteja ancorada em um trabalho defendido em 2013 e, especialmente, pesquisas mais recentes sobre o tema tenham sido realizadas sob diferentes enfoques (MENDONÇA, 2014; SPOLIDORIO, 2017; SIGILIANO; BORGES, 2019), proponho justamente uma atualização do olhar em torno das práticas desses grupos de tradução audiovisual, que me parecem permanecer bastante relevantes para a compreensão das atuais dinâmicas midiáticas, principalmente no que concerne ao cenário brasileiro.

As comunidades de fãs que se destinam à tradução e legendagem de animês - os grupos de fansubs - se originam nas raízes dos clubes de animês surgidos no periodo pré-digital. Esses grupos surgem nos Estados Unidos no final da década de 1970 do intuito dos fãs americanos em promoverem e divulgarem animês e demais conteúdos de mídia asiática no país devido à escassez dessas produções nas midias oficiais (LEONARD, 2005; JENKINS, 2006). Contudo, com o advento dos videocassetes e da tecnologia VHS, esses clubes antes só destinados a exibições, passaram a produzir legendas amadoras. Desse modo, a prática fansubber veio evoluindo nas últimas décadas acompanhando a esteira do desenvolvimento das tecnologias de reprodução e compartilhamento de arquivos e se expandiu entre os demais fãs de outros paises, igualmente interessados nas produções nipônicas (LEE, 2011; CWIEK-ROGALSKA et al., 2015; RONG, 2014).

A principio, valendo-se da tecnologia $\mathrm{VHS}$, que permitiu as primeiras produções de legendas amadoras e, mais recentemente, lançando mão das facilidades da internet e da comunicação $\mathrm{P} 2 \mathrm{P}$, a atividade fansubber se expandiu consideravelmente e ganhou novos contornos em termos de mediação e usos das tecnologias (LEE, 2010, 2011; DENISON, 2011). Atualmente existem muitos fansubs das mais variadas nacionalidades que traduzem animês para diversas linguas, em inúmeras versões diferentes, sendo dificil precisar, quantitativamente, o número de grupos em atuação na rede. Com efeito, os últimos tempos mostraram como a comunidade fansubber passou de uma condição de pouca visibilidade e impacto nos fluxos da cultura midiática na paisagem global para uma posição privilegiada de base de mediação e distribuição (informal, gratuita e especializada) das produções seriadas japonesas para os fãs de muitos paises (LEE, 2011; URBANO, 2013) como é o caso do Brasil, ${ }^{4}$ que apresenta laços historicamente construídos estabelecidos com o Japão, sendo um pais onde a televisão, até certo periodo histórico, desempenhou função de extrema relevância em termos de difusão da cultura animê para os públicos brasileiros (MONTE, 2010; NAGADO, 2007; SATO, 2007, LUYTEN, 2005).

Decerto, a presença dos produtos audiovisuais nipônicos na televisão brasileira desde a década de 1960 e o contexto migratório que marca a relação entre Japão e Brasil são fatores de relevo no que concerne à emergência, nas últimas duas décadas, de um interesse crescente de um nicho de consumidores brasileiros pelos animes (URBANO, 2013). De fato, o interesse em relação às produções audiovisuais nipônicas se tornou tão grande no país na década de 1990, que a

\footnotetext{
2 Aqui neste texto, entendemos os animês enquanto séries de animação japonesas em seu formato serializado para exibição episódica na TV, em DVD ou em serviços de streaming especializados.

3 No caso particular do Brasil, se utiliza a palavra "fansubber" para designar os fãs que realizam tanto a atividade, quanto a prática colaborativa em si.

4 No Brasil, é dificil precisar quando surge o primeiro fansub. Assim como os fãs estadunidenses, os aficionados brasileiros constituíram uma rede informal de troca dessas animações constituida por amigos, conhecidos e demais individuos interessados em animês que se expandiu com a migração para a internet. Alguns fãs concedem ao B.A.C - Brasil Anima Club, grupo surgido em Brasília no ano de 1996 , o título de primeiro fansub brasileiro.
} 
oferta disponivel no mercado brasileiro não foi capaz de satisfazê-los. Além disto, a partir do ano 2000 , essa oferta nas midias oficiais efetivamente decaiu. Por essa razão, os fãs brasileiros interessados neste tipo de material se viram obrigados a recorrerem a outros meios para ter acesso a ele. Sobretudo, os animês encontraram outras vias de mediação e distribuição com o surgimento da prática fansubber no país e sua transposição nesse mesmo periodo para o universo virtual. Naturalmente, o envolvimento ativo e afetivo desses fãs, conjugados às transformações ocorridas nos últimos anos nos campos social, cultural, econômico e tecnológico, tornaram o cenário propício para a configuração de uma cadeia intermediária de mediação de animês, tendo como mediadores e mantenedores seus próprios fãs (URBANO, 2013).

Considerando todo o exposto, o argumento do texto se desenvolve em três seções. Inicialmente, apresento o fandom on-line de animês, a partir das discussões contemporâneas sobre convergência midiática, cultura colaborativa e inteligência coletiva. Longe de ser uma comunidade caracterizada por consenso entre seus membros, a cultura promovida pelos fãs de animês em suas comunidades on-line envolve fortes contradições e divergências. Na segunda seção, apresentamos as premissas éticas e politicas que nortearam as atividades dos fansubbers brasileiros até pouco tempo atrás, de forma a demonstrar como a inserção dos denominados speed fansubs (grupos de velocidade) no circuito fansubber promoveu uma redefinição no ethos dessa comunidade de fãs. Já em um terceiro momento, para fins de apresentação dos procedimentos metodológicos, categorizamos essas políticas tendo em vista os dados que obtivemos a partir de entrevistas densas com os realizadores da atividade, chegando a quatro grandes eixos que, na prática, correspondem mais a tipos ideais de mediação, em boa parte, imaginados por esses fãs, quais sejam: a) politicas socioculturais e linguísticas; b) políticas de qualidade; c) politicas de temporalidade; e d) politicas de acessibilidade e distribuição.

Os eixos dedicaram-se, assim, não só a per- ceber de que modo o capital subcultural e as hierarquias (BOURDIEU, 1989, 2008; NAPIER, 2007; THORNTON, 1996) articuladas nessa comunidade de fãs são demonstradas através dessas políticas de mediação, mas, também, propõem-se avançar na direção de uma concepção mais complexa da organização desse coletivo de fãs. Nesse contexto, o texto enseja, essencialmente, refletir sobre as tensões e as divergências que marcam as dinâmicas contemporâneas, moldando e transformando as relações nessa comunidade de fãs.

\section{O fandom on-line de animês: divergências e disputas por capital subcultural}

As comunidades de fãs são geralmente referidas pela literatura acadêmica através do termo fandom, utilizado para designar coletivos de fãs em torno de um determinado produto cultural, geralmente aportados na internet. De acordo com Henry Jenkins (2006), um dos autores pioneiros nos estudos sobre os fandoms, fazer parte de um fandom significa sair do isolamento sociocultural rumo a uma participação ativa. O autor reconhece os fandoms como coletivos de fãs que, reúnem-se por interesses em comum e partilhado, gerando um senso de pertencimento que não necessariamente precisa de uma interação face a face para se consolidar. Esse sentimento de comunidade seria compartilhado às vezes por até milhares de fãs unidos por dividirem os mesmos interesses, mas também por valorizarem o compartilhamento de experiências, conhecimentos e competências. Esses interesses podem referir-se a qualquer objeto de desejo, quer se trate de um estilo de música ou de um programa de TV, mas o fator determinante desse sistema é a relação estabelecida entre os fãs e um dado texto cultural, ambos tendo a mesma relevância nesse novo meio ambiente. Com efeito, o sistema pelo qual as comunidades de fãs se organizam na rede valoriza o papel do consumidor comum na apropriação de certos textos culturais, sendo esses o ponto de partida natural para a inspiração de múltiplas recriações. Daí o próprio nome do sistema - fandom: "domínio dos fãs". Fandoms são, portanto, sistemas de leitura e de apropriação de textos culturais, que 
podem ser designados por um agrupamento de individuos que dividem interesses, práticas e um sistema de sentido comum.

Não sendo mais um privilégio exclusivo dos grandes conglomerados midiáticos, textos culturais contemporâneos no qual se misturam livros, games, programas e séries de TV, música são apropriados livremente por fãs ativos que se recusam simplesmente em aceitar o que recebem (JENKINS [2009]) e que buscam uma atuação conjunta e/ou paralela aos desenvolvedores das narrativas ficcionais, através da criação de novos produtos culturais e interferência nos já existentes. Recentemente, os fãs através das práticas desenvolvidas em suas comunidades adquiriram um novo status no interior da cadeia mercadológica que envolve a produção cultural globalizada. Por isso, primeiramente, entendemos esses fãs como produsers 5 (BRUNS, 2008), audiências ativas que não só saem à "caça" de seus produtos culturais favoritos (JENKINS, 1992), mas também oferecem múltiplas mediações através do consumo ativo e afetivo de bens culturais.

Essa disposição do fã-consumidor à interação, apropriação e transformação desses artefatos culturais, somado à distribuição rápida, fácil e barata de novos conteúdos e ferramentas, configura o que Jenkins (2009) recentemente denominou como cultura da participação. O autor elucida que "em vez de falar sobre produtores e consumidores de mídia como ocupantes de papéis separados, podemos agora considerá-los como participantes interagindo" (JENKINS, 2009, p. 30). Em outras palavras, a cultura de participação nasce na esteira do discurso otimista sobre o potencial de "criação e transformação sociopolítica do cidadão comum" (CAMPANELLA, 2012, p. 474) no qual se ressalta as muitas transformações advindas do "empoderamento" dos consumidores. Trata-se, pois, de um "convite/oportunidade" aos fãs e consumidores em geral a produzirem e difundirem novos conteúdos gerados a partir de uma matriz ou modelo, ou seja, tendo como inspiração o produto original, daí se daria o diálogo imaginado por Jenkins entre indústrias e consumidores.
Central no pensamento de Jenkins é a ideia que o compartilhamento de saberes e a junção das competências individuais de cada individuo no interior de suas comunidades de conhecimento culminariam no fenômeno da "inteligência coletiva" pensamento que tem suas origens nas ideias de Pierre Lévy (1999a). Esse autor sugere que as comunidades na internet oferecem "um campo de prática mais aberto, mais participativo, mais distribuido que aqueles das mídias clássicas" (LÉVY, 1999a, p. 129). Por isso, na concepção do filósofo francês, através dos usos e mediações nesse novo espaço antropológico de permanente construção do saber - o ciberespaço - é possivel que os membros de um grupo social "se coordenem, cooperem, alimentem e consultem uma memória comum, e isto quase em tempo real, apesar da distribuição geográfica e da diferença de horários" (LÉVY, 1999b, p. 49). É no bojo desse pensamento que Jenkins (2009) apoia seu argumento sobre a constituição real de uma "inteligência coletiva" no tocante às práticas colaborativas que emergem na era da "convergência tecnológica".

O que Jenkins (2009) define como cultura participativa, traduz minha ideia inicial sobre o fandom de animês, cujo fluxo de produção, reprodução, criação e circulação é cada vez mais abrangente. Graças ao desenvolvimento da comunicação eletrônica, as práticas culturais dos fãs de animê também se globalizaram. Por isso, assim como Nancy Baym e Robert Burnett (2009) argumentam, creio também que "juntos, esses fãs servem como filtros de especialistas, pois examinam, separam, rotulam, traduzem, valorizam e anotam uma quantidade grande, desorganizada e geograficamente remota de materiais culturais para consumo internacional" (BAYM; BURNETT, 2009, p. 435, tradução nossa). De fato, ser fã de animê envolve muito mais do que os assistir e os consumir. Em seu próprio aspecto econômico, significa trocar conhecimentos, compartilhar informações e até desenvolver diversas práticas culturais. Mais do que isso: ser fã de animê também envolve tecer discussões e críticas sobre o que é produzido tanto pelo mer-

5 Junção das palavras producer (produtor) e user (usuário). 
cado oficial quanto pelas comunidades on-line dedicadas ao animês, dentre outras questões que envolvem esse circuito na rede e fora dela. Portanto, essas práticas permitem que os fãs acumulem não apenas informações, mas também capital subcultural entre si.

Nos estudos de Susan Napier (2007) sobre os fãs de animês (baseado nas ideias de Sarah Thornton), o capital subcultural articulado nas comunidades de fãs de animês é descrito como "o conhecimento sobre uma determinada área dos fãs que permite interagir com outros fãs, mas também reunir status entre seus colegas entusiastas" (NAPIER, 2007, p. 150, tradução nossa). Portanto, entendo esses fãs como mediadores em potencial que ganham destaque quando se tornam um elo entre os animês (e seus assuntos derivados) e os outros fãs da rede. Eles atuam como intermediários no circuito desse produto cultural, formando preferências e padrões de consumo no decorrer das atividades realizadas em suas comunidades on-line. Nesta medida, são mediadores que ganham destaque e singularidade em suas comunidades, devido às suas práticas e expressões direcionadas a um público ávido por fruir e discutir sobre animês e assuntos correlacionados, e que ganham voz nos espaços de discussão e de produção de conhecimento mantido por esses mediadores na rede.

Dessa forma, a demonstração do capital subcultural articulado no fandom on-line de animês se expressa, fundamentalmente, em conversas sobre variados títulos, e, principalmente, sobre produtos culturais raros e não convencionais. Essa incorporação do capital subcultural se dá tanto na forma de "saber o que é preciso" para interagir e discutir sobre essas produções e, portanto, intermediar o circuito do fandom, estando por dentro das raridades, mas também das novidades, dos lançamentos e modas do momento, relacionadas ao universo não só dos animês, mas da cultura pop japonesa como um todo (URBANO, 2013). Torna-se, então, uma questão considerar esses atributos e conhecimentos como reflexos da autenticidade do produto cultural. Aqueles que demonstram um conhecimento profundo de seu objeto de afeição e desenvolvem certas práticas culturais são elevados nessa comunidade acima daqueles que não possuem o conhecimento distintivo de um "verdadeiro fã". Portanto, embora boa parte do capital do conhecimento dos fãs de animês venha de noções positivas sobre o compartilhamento de paixões e objetivos comuns, é igualmente possivel acumular esse conhecimento por meio de relações mais competitivas e antagônicas.

Neste sentido, acredito que o fandom on-line de animês e suas práticas correlacionadas - como o fansubber - não podem ser analisados apenas sob o foco da colaboração e da inteligência coletiva conforme sugere Jenkins em "fase mais politicamente descontraída de sua carreira" (FREIRE FILHO, 2007, p. 98). Longe de se configurar em um circuito caracterizado pelo consenso entre seus membros, a cultura promovida pelos fãs de animês em suas comunidades on-line envolve fortes contradições e dissensões. Fundamentalmente, pontuamos a forte existência de hierarquias, alianças e rivalidades constituindo a organização de algumas dessas comunidades - como é o caso dos grupos fansubs brasileiros - que podem sobrepor-se às dinâmicas que poderiam levar à formação de uma inteligência coletiva.

Entre fansubs e speed fansubs (e sites de reencodes)

\begin{abstract}
"A atividade de um fansub possui um slogan bem bacana: "Feito de fãs para fãs". É uma frase bem conhecida e tem algumas implicações, a primeira delas sendo a gratuidade. Quem se compromete a desenvolver uma atividade fansubber, seja qual for, deve fazê-la de graça. As doações devem partir das pessoas que se sentem confortáveis em contribuir com o seu trabalho de alguma forma e essa contribuição DEVE SER USADA para manter e melhorar a infra-estrutura do grupo, não para enriquecimento próprio da equipe. Outro principio um tanto implicito, mas que eu gosto de ressaltar é que a gratuidade não deve ser desculpa para trabalho mal feito. Faça o trabalho, faça-o de graça e faça-o da melhor maneira possivel, SEMPRE. Quem não concorda com isso, que não faça, existem outras formas de ajudar que não envolvem tanto comprometimento. Uma terceira prática que gosto muito é a de não se meter nos assuntos de outros grupos. Darei a minha opinião sobre um grupo ou outro só se me perguntarem, mas não ficarei 'semeando o mal'".
\end{abstract}

(Jihox, Anime no Sekai Fansub) 
No relato apresentado na epigrafe acima, o informante Jihox apresenta uma concepção bastante interessante sobre os aspectos que permeiam a conduta fansubber no fandom de animês. Em nossa análise, a frase acima pode ser usada como boa ilustração de um ethos tradicional ainda bastante latente na comunidade fansubber brasileira. Na primeira tem-se o aspecto da "gratuidade", caracterizado pela conhecida premissa "de fã para fã". A seguir, o estudante fluminense aponta a existência de um valor implícito fundamental que guiaria a atividade desses grupos na rede, a seu ver, inseparável da questão da gratuidade: a "qualidade" final de suas produções amadoras. Por último, Jihox esboça uma opinião (ainda tímida) quando o assunto são as práticas de outros grupos em atuação na rede.

O que a fala de Jihox aponta é a existência de certas premissas éticas, valores e hierarquias que representam um sistema tradicional de organização pelo qual a comunidade fansubber estaria submetida historicamente e socialmente desde seu surgimento. Entretanto, se até certo momento histórico, esse dado coletivo de fãs pudesse ser definido por essas premissas, porém, em um curto intervalo de tempo, essa comunidade se modificou em função de novas circunstâncias sociais, culturais e tecnológicas. Com efeito, as novas práticas, os novos atores sociais e as políticas que emergiram nesse novo meio ambiente, demonstram como o ethos da comunidade fansubber - historicamente e socialmente construido - naturalmente é suscetivel aos efeitos de mutabilidade do tempo. De fato, algumas das principais questões reveladas por nossos informantes ao longo das entrevistas e observação participante apontam para o estabelecimento de mediações diversas - como as promovidas pelos speed subs e sites de reencode - que, antes de tudo, evidenciam o amplo campo de disputas e conflitos nessa comunidade.

Historicamente, a comunidade fansubber se fundamentou sob um lema essencial que visava nortear a atividade dos grupos e de seus membros no fandom de animês: o "de fã para fã". Mais do que um lema que, por sua vez, demonstra o caráter abnegado da atividade fansubber, o que ele denuncia é a existência de um ethos tradicional que foi sendo construído na comunidade fansubber, sendo eficaz até pouco tempo atrás para regular as relações e as ações dos membros nessa comunidade no decorrer de suas atividades colaborativas.

Contudo, o meio ambiente dessa comunidade de fãs é um pouco mais complexo do que o idealizado. Atualmente, os grupos de tradução brasileiros dividem-se em dois tipos fundamentais em termos de organização: fansubs e speed fansubs. Os primeiros são grupos firmemente centrados em torno de um ethos tradicional, ancorados em um código de conduta histórico e que possuem uma visão bastante ortodoxa em torno da prática que desenvolvem em suas comunidades. Já os segundos, representam um novo ethos, ligado também a outros interesses e que emergem como a mais recente novidade nesse circuito. Esses novos grupos, que foram pouco a pouco sendo incorporados pela comunidade fansubber, operam sob uma lógica mais contemporânea, centrada na instantaneidade da mediação e no consumo da velocidade em si. Embora seja prudente ressaltar que as fronteiras que demarcam as atividades dos fansubs e speeds subs sejam fluidas e, em boa medida, esses critérios tradicionais estejam bastante latentes nessa comunidade como um todo, é interessante perceber as aproximações e os afastamentos entre esses dois modelos de mediação concebidos dentro dessa mesma comunidade de fãs.

Em primeiro lugar, tem-se o fato de que, historicamente, os fansubs não visam beneficio financeiro na atividade que desenvolvem (nem para si, nem para seus membros), logo, não vendem os seus animês traduzidos e nem outros produtos correlacionados em seus espaços virtuais. Por isso muitos grupos, como os investigados nessa pesquisa ${ }^{6}$ dispõe do seguinte aviso em seus titulos legendados "Anime feito por fãs para fãs, não venda ou alugue". Aliás, o envolvimento e o

\footnotetext{
6 Os grupos fansubs contemplados nessa pesquisa foram o Ryussei Fansubs, Eternal Animes Fansub, OMDA Fansubs, Sukinime, Seitokai e Anime No Sekai (URBANO, 2013, p. 88).
} 
retorno financeiro não seriam compativeis com os principios fins dessa atividade colaborativa. No entanto, nossos informantes enfatizaram que as atividades atuais dos grupos de tradução envolvem não só um investimento intelectual e cultural de seus membros para ganharem forma. Particularmente, essas atividades requerem dos próprios fansubbers, e em boa parte dos casos, de sua audiência-fã certo investimento financeiro, mas também simbólico, para sua manutenção (dos links, websites, portais etc.). De modo a minimizar as despesas, boa parte dos fansubs brasileiros dispõe de sistemas de doação, outros atuam através de meios mais profissionais, envolvendo um sistema de troca de prestações materializados em taxas fixas de upload/download para seus usuários e, nos casos mais extremos (e polêmicos), cobrando valores em dinheiro para um acesso VIP aos títulos legendados. De maneira geral, a ideia é que a comunidade - composta pelos fansubbers e sua audiência-fã - possa colaborar efetivamente para manter seus animês favoritos on-line e, consequentemente, assegurar a permanência da atuação do fansub no qual costuma fazer seus downloads.

Em segundo lugar, os fansubs brasileiros, em certa medida, trabalham com animês não licenciados em seus países, quando um anime é licenciado em seu país, o fansub para de legendar o mesmo. Uma exceção é feita quando o licenciador pretende editar o conteúdo pesadamente sem liberar uma versão sem cortes. Tendo como justificativa o trânsito escasso de animês no mercado global, essas versões disponibilizadas pelos fãs-tradutores atuariam na divulgação de títulos inéditos de animês, sobretudo, aqueles ainda não licenciados para exibição em seus países. Um caso que particularmente ilustra essas questões é o do Dattebayo fansub, grupo de fã-tradução americano que em 2008 cessou a distribuição da série Naruto devido à aquisição dos direitos pela empresa americana de distribuição Viz Media. Não obstante, recordamos que nesse mesmo período, uma parcela dos fansubs brasileiros que trabalhavam com o referido título também retirou o anime de seus catálogos on-line seguindo o exemplo dos fãs americanos. Na medida em que Naruto esteve em exibição na TV brasileira de 2007 até abril de 2011, data que marcou a veiculação do último episódio da saga no Cartoon Network, alguns grupos brasileiros perceberam que já não era mais necessário dar continuidade à sua divulgação na rede. Entretanto, são muitos os motivos que levam os fansubs a iniciarem ou darem fim a um projeto e, não necessariamente, a aquisição dos direitos por distribuidoras locais se impõem enquanto empecilho para as atividades desses grupos em seus paises.

Em última análise, como o trabalho feito pelos fansubs não visa lucro algum, não haveria um dia específico, nem uma periodicidade estipulada para a distribuição dos episódios legendados. Entendendo que a prática fansubber foi descrita pelos nossos informantes como um tempo de lazer, um hobby organizado, guiado pela devoção ao produto cultural em questão, percebemos que alguns critérios ganham relevância entre os fansubs tradicionais em detrimento a outros. Sobretudo, a ausência de sazonalidade proclamada por essa última premissa revela uma oposição nessa comunidade a qualquer lógica que remeta às dinâmicas de temporalidade do mercado oficial. O diferencial de mediação dos fansubs tradicionais, portanto, residiria na valorização de critérios como qualidade (visual e textual de suas reproduções), em detrimento a uma lógica massiva de mediação e de distribuição, tal como aquela encerrada pelo mercado e, mais recentemente, pelos grupos que atuam em nivel speed.

Os speed fansubs e, também, os chamados sites de reencode, encontram-se na contracorrente desse modelo de mediação descrito. Ambas as propostas se caracterizam por promoverem uma nova mediação calcada na velocidade, na rapidez da distribuição e na facilidade na aquisição dos animês na rede. Porém, enquanto os speeds subs operam sob uma lógica de produção propriamente dita (isto é, produzem legendas) semelhante as dos grupos tradicionais, os segundos, os reencodes, são grupos formados tendo em vista a replicação/redistribuição dos projetos dos fansubs e, principalmente, daqueles grupos que atuam em 
nível speed dentro de uma proposta mais ampla de divulgação da cultura pop japonesa. A questão que se colocou nas discussões via Skype junto aos informantes dessa pesquisa é que os sites de reencodes não produzem um trabalho "original" e dependem da produção dos fansubs e, sobretudo, da velocidade imposta pelos speeds para funcionarem plenamente já que boa parte da audiência desses grupos integra-se à proposta de velocidade proclamada pelos speeds.

Naturalmente, a velocidade se impõe enquanto ferramenta competitiva nessa comunidade de fãs na contemporaneidade e suas consequências são devidamente sentidas na mediação exercida por essa comunidade de fãs. Mais do que ampliar o repertório de títulos e a velocidade dos lançamentos, a adição de novas maneiras de "legendar e distribuir" os animês, significativamente, alterou os modos pelos quais a atividade funcionava desde seu surgimento. Uma vez que a prioridade dos grupos de velocidade reside no quesito "velocidade", algumas questões como "qualidade" e "autenticidade" (sobretudo do texto), bem como associações com práticas comerciais, naturalmente passam a ser passiveis de discussão por se oporem, em certa medida, às premissas históricas que guiaram as atividades dessa comunidade até pouco tempo atrás.

A questão é o imediatismo. Entra a questão tipo "Punch", porque foi o primeiro fansub que descaradamente começou com isso. Eles legendam rápido, tem muitos views, ficaram muito conhecidos porque geralmente esses sites de reencodes pegam do primeiro fansub que lança, não interessa qual seja, depois eles até mudam. O Punch legenda rápido, tem muito viewer e muito leechers, que querem o anime pra ontem [...] Mas o problema é a questão ética. E seus pedidos de doações de 700 reais utilizados para outros fins (Anissina Keiko, Sukinime Fansub, informação verbal). ${ }^{7}$

O lema "De fã para fã" é uma pratica que é seguido pela maioria dos fansubs sérios, que visam apenas a distribuição dos animês para todos sem visar lucro, mas nesse meio tem algum fansubs que comercializam isso, ven- dendo animês, camisetas, e todo tipo de coisas que possam mais ser caracterizados como Pirataria do que como fansub. Nesse ponto quem mais faz isso são os speedsubs, fansubs que não se preocupam com qualidade e sim com velocidade. Como foi dito não vou citar nomes apenas digo que um grande exemplo é o Grupo que começa com "P" e termina com "unch" é um exemplo disso como seus aliados da "Project". São a meu ver um exemplo de quem não segue esse lema (Aracraud, Ryussei Fansubs, informação verbal). ${ }^{8}$

Primordialmente, observou-se que a geração que atua há mais tempo como fansubber é propensa a desprezar as práticas dos grupos de velocidade e dos sites de reencode, que cada vez mais crescem em amplitude e visibilidade junto aos demais fãs de animês na rede. A grande questão é que na opinião de alguns de nossos informantes, a velocidade possibilitada pelos speed subs fere, significativamente, os códigos norteadores próprios à comunidade fansubber. Mais do que isso: as atividades que envolvem a atuação de alguns grupos que atuam em nivel speed na comunidade fansubber constituem-se no cerne dos conflitos e das divergências que permeiam esse agrupamento de fãs. Termos como "lixo subs", "câncer dos fansubs" dentre outras formas pejorativas foram atribuidas aos grupos de velocidade por nossos informantes ao longo da pesquisa.

Com o surgimento de muitos "fansubs" que não prezam a qualidade e fazem um serviço de qualquer jeito (leia-se Lixosubs como são chamados.) o nivel do Fansub nacional caiu muito levando à situação atual onde alguém que aprende a usar o Google translator e "aprende a encodar" monta um "fansub". Hoje a maioria preza velocidade e uma minoria prefere aguardar um pouco mais e pegar algo de qualidade (ShionTNT, Eternal Animes, informação verbal). ${ }^{9}$

Enquanto uma minoria de nossos informantes mostrou-se otimista e/ou pouco afetados pelo crescimento exponencial da comunidade fansubber, marcado principalmente pelo surgimento das novas possibilidades técnicas de produção e

\footnotetext{
7 Depoimento concedido à pesquisadora através de questionário aplicado on-line e entrevista individual realizada via Skype entre os meses de agosto a dezembro de 2012.

8 Depoimento concedido à pesquisadora através de questionário aplicado on-line e entrevista individual realizada via Skype entre os meses de agosto a dezembro de 2012.

9 Depoimento concedido à pesquisadora através de questionário aplicado on-line e entrevista individual realizada via Skype entre os meses de agosto a dezembro de 2012.
} 
de distribuição, outros apresentaram uma visão bastante pessimista em torno da popularização da prática no Brasil. A maioria de nossos informantes mencionou haver um desgaste na comunidade fansubber ocasionado pela popularização da prática entre os demais fãs, o que vem promovendo a emergência de novas práticas e grupos que não comungam dos mesmos códigos tradicionais que compõem a comunidade desde seu surgimento

De modo a compreender essas disputas evidenciadas entre os fansubbers brasileiros, apresentamos as políticas de mediação vigentes nessa comunidade, dentro de uma proposta de classificação e análise dos critérios valorativos que presidem o modelo de mediação ainda em voga nessa comunidade de fãs.

\section{As políticas de mediação dos}

\section{fansubbers brasileiros: procedimentos metodológicos}

Com o objetivo de situar a complexidade dessas dinâmicas entre os fansubbers brasileiros e, sobretudo, para fins de distinção entre fansubs e speed fansubs, categorizamos as politicas que envolvem a mediação promovida por essa comunidade tendo em vista os dados que obtivemos, chegando-se a quatro grandes eixos que, na prática correspondem mais a tipos ideais de mediação, em boa parte, imaginada por esses fãs, quais sejam: a) politicas socioculturais e linguísticas; b) politicas de qualidade; c) politicas de temporalidade e; d) políticas de acessibilidade e distribuição. Tais eixos, portanto, devem ser entendidos como ferramentas de análise tendo em vista a estruturação dos dados obtidos (ver Tabela 1 e Tabela 2).

TABELA 1 - Políticas de mediação dos fansubs brasileiros nas redes digitais

\begin{tabular}{lcccc}
\hline & Politicas & Políticas de & Politicas de \\
de análise & $\begin{array}{c}\text { socioculturais e } \\
\text { linguísticas }\end{array}$ & $\begin{array}{c}\text { Políticas de } \\
\text { qualidade }\end{array}$ & $\begin{array}{c}\text { temporalidade } \\
\text { acessibilidade e } \\
\text { distribuição }\end{array}$ \\
\hline
\end{tabular}

- Tradução como etapa principal e mais relevante de todo o processo.

- Preferência por tradutores que dominem a língua japonesa, seguido do inglês.

Fansubs

- Idiossincrasias culturais presentes nos textos anime valorizadas na tradução.

- Valorização do áudio original em japonês conferindo "niponicidade" à experiência sonora e imagética com os animês.
- Noção de qualidade historicamente e socialmente construida nesse coletivo de fãs.

- Critérios de qualidade bastante particulares e que se diferem daqueles aplicados ao produto oficial.

- Experiência textual-sonora-imagética autêntica com os animês.

- Estética mais artesanal em suas legendas, baseadas na idéia do excesso.
- Produção e distribuição dos títulos temporalmente descontinua.

- Ética de cooperação voluntária, se caracterizando por um tempo de lazer igualmente descontínuo.

- Oposição as dinâmicas de produção e distribuição do mercado oficial.

- Qualidade de tradução, imagem e legendas em detrimento à velocidade de acesso e distribuição.
- Acesso e distribuição gratuita via torrent, com trackers ativos para downloads.

- Sistema de Ratio: "medida de generosidade" (fansubs e usuários).

- Sistema mantido financeiramente através das doações dos usuários (sobrevivência dos trackers).

- Lógica artesanal de acesso e distribuição.

- Predominância de títulos de difícil acesso, já exibidos no Japão.

Fonte: Tabela adaptada da discussão em Urbano (2013, p. 130-150). 
No primeiro eixo, elencamos as políticas socioculturais e linguísticas que norteiam a constituição dos fansubs e speed fansubs. Essas políticas tornaram-se visiveis quando observamos os critérios de escolha dos grupos em relação aos seus membros, principalmente através das competências valorizadas entre os fansubbers para um trabalho final satisfatório em seus grupos. Já no segundo eixo, exploramos mais especificamente, como a busca por uma experiência nipônica e autêntica no decorrer do processo de produção fansubber se reflete no estabelecimento de certos padrões de qualidade (não só textual e visual, mas também em termos de velocidade) dos títulos trabalhados pelos grupos investigados. No terceiro eixo, investigamos as políticas relacionadas à temporalidade, contemplando desde a produção à distribuição de títulos encerrada pelos fansubs e speed fansubs investigados. Aqui, entram em jogo os ideais de qualidade e de autenticidade construidos nessa comunidade tradicionalmente, que se opõem a uma lógica temporal de produção e de distribuição centrada na instantaneidade, isto é, no consumo da velocidade (VIRILIO, 1996; BOOTH, 2010), uma tendência contemporânea das audiências. E, por fim, no quarto eixo discutimos sobre as politicas que envolvem a acessibilidade e a distribuição dos títulos legendados pelos grupos contemplados na pesquisa.

TABELA 2 - Políticas de mediação dos speed fansubs brasileiros nas redes digitais

\begin{tabular}{|c|c|c|c|c|}
\hline $\begin{array}{l}\text { Categorias } \\
\text { de análise }\end{array}$ & $\begin{array}{c}\text { Políticas } \\
\text { socioculturais e } \\
\text { linguísticas }\end{array}$ & $\begin{array}{l}\text { Politicas de } \\
\text { qualidade }\end{array}$ & $\begin{array}{c}\text { Politicas de } \\
\text { temporalidade }\end{array}$ & $\begin{array}{l}\text { Políticas de } \\
\text { acessibilidade e } \\
\text { distribuição }\end{array}$ \\
\hline $\begin{array}{l}\text { Speed } \\
\text { Fansubs }\end{array}$ & $\begin{array}{l}\text { - Tradução como } \\
\text { etapa principal e } \\
\text { mais relevante de } \\
\text { todo o processo. } \\
\text { - Predominância } \\
\text { de tradutores que } \\
\text { dominam o inglês, } \\
\text { mas que tenham } \\
\text { conhecimentos no } \\
\text { universo anime. } \\
\text { • Processo de } \\
\text { re-tradução dos } \\
\text { scripts em inglês. } \\
\text { - Idiossincrasias } \\
\text { culturais frequen- } \\
\text { temente supri- } \\
\text { midas nos textos } \\
\text { traduzidos. }\end{array}$ & $\begin{array}{l}\text { • Noção de qua- } \\
\text { lidade atrelada à } \\
\text { padronização das le- } \\
\text { gendas e velocidade } \\
\text { de distribuição. } \\
\text { • Critérios de } \\
\text { qualidade bastante } \\
\text { próximos daqueles } \\
\text { aplicados ao pro- } \\
\text { duto oficial (clean). } \\
\text { • Estética mais } \\
\text { padronizada e } \\
\text { simplificada nas } \\
\text { legendas. }\end{array}$ & $\begin{array}{l}\text { • Produção e distri- } \\
\text { buição dos títulos/ } \\
\text { episódios a poucas } \\
\text { horas de seu lança- } \\
\text { mento oficial. } \\
\text { • Velocidade acom- } \\
\text { panhando a tendên- } \\
\text { cia das audiências } \\
\text { em estarem cada } \\
\text { vez mais próximas } \\
\text { dos ritmos de difu- } \\
\text { são dos lançamen- } \\
\text { tos no Japão. } \\
\text { • Velocidade de dis- } \\
\text { tribuição consumida } \\
\text { como fetiche no } \\
\text { fandom de animês. }\end{array}$ & $\begin{array}{l}\text { • Acesso e distri- } \\
\text { buição geralmente } \\
\text { gratuita via torrent, } \\
\text { com trackers ativos } \\
\text { para downloads. } \\
\text { • Lógica de acesso } \\
\text { e distribuição mais } \\
\text { próxima do mercado } \\
\text { oficial. } \\
\text { • Predominância de } \\
\text { animês populares e } \\
\text { em exibição distribuí- } \\
\text { dos por esse coletivo } \\
\text { de fãs. } \\
\text { • Junção de "econo- } \\
\text { mia de mercado" e } \\
\text { "economia da dádiva": } \\
\text { caso PuNCH Fansubs. }\end{array}$ \\
\hline
\end{tabular}

Fonte: Tabela adaptada da discussão em URBANO (2013, p. 130-150).

O resultado dessa investigação demonstrou que, enquanto os grupos fansubs são firmemente centrados em torno de um ethos tradicional, ancorados em um código de conduta histórico e possuindo uma visão bastante ortodoxa em torno da prática que desenvolvem em suas comunidades, os grupos que atuam em nivel speed nessa comunidade de fãs representam um novo ethos, ligado a conceitos como velocidade e web-presença, emergindo como a mais recente novidade e conquistando um lugar de destaque nesse circuito (URBANO, 2013).

Sendo assim, ao invés de constituírem um circuito de colaboração ideal, mutuamente soli- 
dário ou afetivo em seus grupos, os fansubbers brasileiros vêm operando cada vez mais em um ambiente competitivo e conflituoso, marcado principalmente pelo surgimento das novas possibilidades técnicas de produção e de distribuição, a chegada de novos membros e de novas práticas que passaram a compor, consequentemente, o escopo da experiência de uma parcela significativa desses grupos (URBANO, 2013, p. 127). Por esses motivos, defendemos que há um processo de redefinição nas formas de mediação atualmente em curso nessa comunidade que se atrela, fundamentalmente, a tendência cada vez mais crescente à velocidade, o que vem modificando as bases artesanais (CAMPBELL, 2004) que guiaram essa comunidade até pouco tempo atrás.

Dito isso, defendemos aqui que o olhar ortodoxo recorrente em torno da cultura fã pela literatura acadêmica fundamental (JENKINS, 2009; LÉVY, 1999a, 1999b), que pressupõem a constituição de um espaço colaborativo, onde seus membros estariam isentos das tensões e dos antagonismos sociais, apresenta uma concepção que vem se revelando frequentemente inadequada e simplificadora, não correspondendo à complexidade das dinâmicas dos fandoms e, principalmente, dos fansubs brasileiros.

É certo que Lévy (1999a, p. 29) afirma que "a base e o objetivo da Inteligência Coletiva são o reconhecimento e o enriquecimento mútuos das pessoas" e que essa se dá em uma espécie de comunidade onde se "assume como objetivo a negociação permanente da ordem estabelecida, de sua linguagem, do papel de cada um, o discernimento e a definição de seus objetos, a reinterpretação de sua memória" (LÉVY, 1999a, p. 31). Já para Jenkins (2009) que se inspirou nas teorias desse autor, essas novas comunidades que emergem nas redes digitais seriam "definidas por afiliações voluntárias, temporárias e táticas, e reafirmadas através de investimentos emocionais e empreendimentos intelectuais comuns" (JENKINS, 2009, p. 57). Por isso, ainda que essas noções sejam particularmente relevantes no que concerne às práticas e às dinâmicas internas da comunidade fansubber, as relações estabeleci- das entre os fansubbers são mais ambiguas e conflituosas do que como descritas por Jenkins que, por exemplo, acredita que "estamos testemunhando uma convergência dentro do cérebro dos consumidores individuais e em suas interações sociais com outros" (JENKINS, 2009, p. 30).

Longe de serem frias ou harmoniosas, as dinâmicas existentes na comunidade fansubber revelam o estabelecimento de disputas e de tensões entre seus membros quando o assunto são os outros grupos e seus modos de produção e distribuição. Dito isso, acreditamos que há um ethos tradicional na comunidade fansubber, semelhante aqueles observados nas culturas clubbers investigadas por Thornton (1996), que tentaria se afirmar por meio de uma oposição a uma ideia geral de mainstream. Ou, sendo mais enfática - no caso dos fansubbers brasileiros - de evitar qualquer associação com uma percepção mais comercial e/ou profissional envolvendo suas práticas e modos de organização e distribuição do fansub. De fato, a relação entre fansubs e speed subs revela as complicações do "trabalho que não é trabalho", o que nos aproxima da discussão de Thomas Lamarre (2004) no caso especifico da cultura otaku: "O movimento otaku - como trabalho não oficial - é ao mesmo tempo trabalho e não trabalho" (LAMARRE, 2004, p. 168, tradução nossa).

Porém, observamos que ao mesmo tempo em que esse ethos ortodoxo é extremamente valorizado nessa comunidade de fãs - inclusive entre os membros dos speed fansubs (conforme relato de Jihox apresentado do início do paper), os fansubs com maior visitação (como os speed subs) também acabam ganhando posição e visibilidade dentro da comunidade. Além disso, encontramos evidências de que há um desejo premente entre alguns desses fansubbers em atuarem no mercado profissional, explorando as habilidades que dedicam ao promoverem uma mediação amadora através do fansub, como é o caso de um dos nossos informantes, Chiaki-Senpai que, divide-se entre as atividades do Seitokai animes e o serviço de streaming de animes Crunchyroll (URBANO, 2013). Ademais, essa parece ser uma tendência que outros ser- 
viços de streaming - como o Viki, o Drama Fever e a Netflix - vêm adotando nos últimos cinco anos, ao agregar os fansubbers brasileiros em seu processo mercadológico de tradução e de produção de legendas profissionais.

Com efeito, há um retorno do trabalho colaborativo promovido pelos fansubs e speed fansubs, sobretudo, para seus membros em suas mais variadas formas. Esse retorno se dá não só por meio de doações para os grupos, mas, principalmente, se materializa no reconhecimento das habilidades individuais de seus agentes (seja pelo mercado ou pela sua audiência fã). Sejam fansubs ou speed fansubs, ambos convivem e se integram, em certa medida, aos anseios e às expectativas de uma audiência-fã plural que também apresenta prioridades diversas quando o assunto são os modos de fruição dos animês. No entanto, acreditamos que certas práticas que emergem na comunidade fansubber fornecem um ganho em termos de visibilidade para os grupos brasileiros, mas também ocasionam um déficit em reputação junto à comunidade brasileira de fansubbers e, também, no fandom de animês ambientado nas redes digitais.

\section{Considerações finais}

Os modos de distribuição promovidos pelos fansubbers em suas comunidades on-line ilustram a maneira como os fãs de animês buscam cada vez mais adquirir essas produções no Brasil. Longe de constituir um fenômeno isolado, as formas alternativas dos fãs no consumo de conteúdos audiovisuais de outros países levam, acima de tudo, a destacarmos a relevância de novas mídias na propagação e na distribuição de produções audiovisuais contemporâneas. A comunidade fansubber contribuiu diretamente para estabelecer uma circulação maior não apenas de animês, mas também de outros formatos televisivos e audiovisuais, como dramas de TV, reality shows e talk shows produzidos e compartilhados entre os países do Leste Asiático, atendendo à demanda que o mercado oficial não conseguiu satisfazer.

Além disso, através da mediação promovida pelo trabalho colaborativo desenvolvido nessa comunidade, muitos títulos de animês de vários gêneros, formatos e vertentes temáticas, que de outra forma não alcançariam o mercado local brasileiro, são lançados para outros fãs nessas comunidades. Por meio de uma lógica de distribuição específica (informal, gratuita e especializada), usando as facilidades oferecidas pelas tecnologias de produção e distribuição, a prática fansubber passou de um hobby amador para constituir o principal núcleo da distribuição de animês para os fãs brasileiros.

Por isso, em vez de enfatizar os pressupostos teóricos que celebram as dinâmicas da cultura colaborativa e da inteligência coletiva, ambos frequentemente associados às práticas e às discussões em torno da cultura de fãs, segui por outro caminho que me permitiu compreender o significado das múltiplas mediações reveladas por nossos informantes, que configuram atualmente as políticas que regem essa comunidade de fãs. As combinações dessas propostas divergentes dos fansubs e dos speed fansubs mostraram como essa comunidade de fãs é rica em disputas por status, legitimidade e capital subcultural.

\section{Referências}

ANNET, Sandra. Imagining Transcultural Fandom: Animation and Global Media Communities. Transcultural Studies, [s. l.], v. 2, n. 2, p. 164-188, dez. 2011.

BAYM, Nancy; BURNETT, Robert. Amateur Experts: International Fan Labor in Swedish Independent Music. International Journal of Cultural Studies, [s. l.], v. 12, n. 5. p. 433449, 2009. https://doi.org/10.1177/1367877909337857

BOOTH, Paul. Digital Fandom: new media studies. New York: Peter Lang Publishing, 2010. https://doi. org/10.3726/978-1-4539-1654-4

BOURDIEU, Pierre. O mercado dos bens simbólicos. In: BOURDIEU, Pierre. A economia das trocas simbólicas. São Paulo: Perspectiva, 1974

BOURDIEU, Pierre. A distinção: critério social do julgamento. Porto Alegre: Zouk, 2008.

CAMPANELLA, Bruno. O fã na cultura da divergência: hierarquia e disputa em uma comunidade on-line. Contemporânea: Revista de Comunicação e Cultura, Salvador, v. 10, n. 3, p. 474-489, 2012.

CAMPBELL, Colin. O consumidor artesão: cultura, artesania e consumo em uma sociedade pós-moderna. Antropolitica, Niterói, n. 17, v. 2, p. 45-67, 2004.

CHIN, Bertha; MORIMOTO, Lori Hitchcock Morimoto. Towards a Theory of Transcultural Fandom. Participations: Journal of Audience \& Reception Studies, [s. l.], v. 10, n. 1, p. 92-108, 2013. 
COOPER-CHEN, Anne. Cartoon planet: the cross-cultural acceptance of Japanese animation. Asian Journal of Communication, [s. l.], v. 22, n. 1, p. 44-57, 2012. https:// doi.org/10.1080/01292986.2011.622774

ĆWIEK-ROGALSKA, Karolina; HOŁY-ŁUCZAJ, Magdalena; $Ł U C Z A J$, Kamil. Fansubbers. The case of the Czech Republic and Poland. Journal of Comparative Research in Anthropology and Sociology, [s. l.], v. 5, n. 2, p. $175-198,2014$

DENISON, Rayna. Anime fandom and the liminal spaces between fan creativity and piracy. International Journal of Cultural Studies, [s. l.], v. 14, n. 5. p. 449-466, 2011. https://doi.org/10.1177/1367877910394565

DÍAZ-CINTAS, Jorge; MUÑOZ-SÁNCHEZ, Pablo. Fansubs: audiovisual translation in an amateur environment. The Journal of Specialised Translation, [s. l.], n. 6, p. 37-52, jul. 2006.

FERRER SIMÓ, María Rosario. Fansubs y scanlations: la influencia del aficionado en los criterios profesionales. Puentes, La Plata, AR, n. 6, p. 27-43, 2005

FREIRE FILHO, João. Reinvenções da resistência juvenil: Os estudos culturais e as micropolíticas do cotidiano. Rio de Janeiro: Mauad, 2007.

IWABUCHI, Koichi. Recentering Globalization: Popular Culture and Japanese Transnationalism. London: Duke University Press, 2002. https://doi. org/10.1215/9780822384083

JENKINS, Henry. Cultura da Convergência. São Paulo: Aleph, 2009

JENKINS, Henry. When piracy becomes promotion: how unauthorized copying made Japanese animation profitable in the United States. Reason Online, dez. 2006. Não paginado.

JENKINS, Henry. Textual Poachers: Television Fans and Participatory Culture. New York: Routledge, 1992.

LAMARRE. Thomas. An introduction to Otaku Movement. Enter Text, [s. l.], v. 4, n. 1, p. 151-187, 2004.

LEE, Hye-Kyung. Cultural consumer and copyright. Creative Industries Journal, [s. l.], v. 3, n. 3, p. 235-250, 2010. https://doi.org/10.1386/cij.3.3.237_1

LEE, Hye-Kyung. Participatory media fandom: A case study of anime fansubbing. Media Culture Society, [s. l.], v. 33, n. 8. p. 1131-1147, 2011. https://doi. org/10.1177/0163443711418271

LEONARD, Sean. Progress against the law: anime and fandom, with the key to the globalization of culture. International Journal of Cultural Studies, [s. l.], v. 8, n. 3, p. 281305, 2005. https://doi.org/10.1177/1367877905055679

LÉVY, Pierre. A inteligência coletiva: por uma antropologia do ciberespaço. 2. ed. Tradução de Luiz Paulo Rouanet. São Paulo: Loyola, 1999a.

LÉVY, Pierre. Cibercultura. São Paulo: editora 34, 1999b.

LUYTEN, Sonia Bibe. Cultura Pop Japonesa: mangá e anime. São Paulo: Hedra, 2005

MONTE, Sandra. A presença do animê na TV brasileira. São Paulo: Ed. Laços, 2010.
MENDONÇA, Bruno Henrique Marques de. Modos de compartilhamento dos grupos de legendas: utilização das redes sociais e dos dispositivos da cultura digital para a produção de legendas artesanais. Dissertação (Mestrado em Comunicação e Linguagens) - Universidade Tuiuti do Paraná, Curitiba, 2014.

NAGADO, Alexandre. Almanaque da Cultura Pop Japonesa. Via Lettera, 2007.

NAPIER, Susan. From Impressionism to Anime: Japan as Fantasy and Fan Cult in the Mind of the West. Basingstoke: Palgrave Macmillan, 2007

RONG, Zongxiao. Hybridity within peer production: The power negotiation of Chinese fansub groups. Dissertation (MSc in Media, Communication and Development) - Department of Media and Communications, London School of Economics and Political Science, 2014

SATO, Cristiane A. Japop. O poder da cultura pop japonesa. São Paulo: NSP-Hakkosha, 2007.

SIGILIANO, Daiana; BORGES, Gabriela. Fansubbing: o diálogo entre a competência midiática e a produção dos fãs da ficção seriada. Animus: Revista Interamericana de Comunicação Midiática, Santa Maria, RS, v. 18, n. 38, p. 249-268, 2019. https://doi.org/10.5902/2175497736067

SPOLIDÓRIO, Samira M. Comunidades Online e Legendas de Fãs: Novas Formas de Produzir e Consumir Legendas. Campinas. Dissertação (Mestrado em Linguistica Aplicada) - Instituto de Estudos da Linguagem (UNICAMP), Campinas, 2017

THORNTON, Sarah. Club cultures: Music, media and subcultural capital. Connecticut: Wesleyan University Press, 1996.

URBANO, Krystal Cortez Luz. Legendar e distribuir: o fandom de animês e as políticas de mediação fansubber nas redes digitais. Dissertação (Mestrado em Comunicação) - Instituto de Arte e Comunicação Social, Universidade Federal Fluminense, Niterói, 2013.

VIRILIO, Paul. Velocidade e política. São Paulo, Estação Liberdade, 1996

\section{Krystal Cortez Luz Urbano}

Doutora em Comunicação pela Universidade Federal Fluminense, com Mestrado em Comunicação pelo mesmo programa; professora da Universidade Federal Fluminense (UFF), em Niterói, RJ, Brasil; coordenadora adjunta do Grupo de Pesquisa em Midia e Cultura Asiática Contemporânea (MidiÁsia).

\section{Endereço para correspondência}

Krystal Cortez Luz Urbano

Universidade Federal Fluminense

Pró-Reitoria de Pesquisa e Pós-Graduação

Rua Tiradentes Ingá

24220900

Niterói, RJ, Brasil 